\title{
PENGGUNAAN PERMAINAN DALAM PENGAJARAN BAHASA INGGRIS BAGI GURU-GURU MADRASAH IBTIDAIYAH MUTA'ALIMIN DAN MADRASAH IBTIDAIYAH HIDAYATUL MUBTADI'IN
}

\author{
Ira Miranti ${ }^{1)}$ Nurjanah $^{2)}$, Nina Dwiastuty ${ }^{3)}$ \\ Program Studi Pendidikan Bahasa Inggris Fakultas Bahasa dan Seni Universitas Indraprasta PGRI
}

\begin{abstract}
Abstrak
Dalam pembelajaran Bahasa Inggris hal yang terpenting adalah bagaimana menarik siswa untuk menyukai pelajaran bahasa Inggris, apabila mereka sudah menyukai dan menyenangi suatu pelajaran maka mereka dapat menguasai pelajaran tersebut.Jadi konsep pembelajaran bahasa Inggris di Madrasah Ibtidaiyah dapat dilakukan dengan learning by playing (belajar sambil bermain). Apabila guru mengajarkan bahasa Inggris dengan metode ceramah maka anak-anak akan merasa bosan. Pembelajaran bahasa Inggris dengan permainan dapat membuat suasana belajar menjadi asik, menarik dan menyenangkan sehingga siswa termotivasi untuk mempelajari dan memahami materi yang diajarkan.
\end{abstract}

Kata Kunci: Permainan., Bahasa Inggris, Pembelajaran

\begin{abstract}
In learning English the most important thing is how to attract students to like English. If they aready like and enjoy a leson, so they can master the lesson. So, the concept of learning English in Madrasah Ibtidaiyah can be done by learning by playing. If the teacher teaches English using the lecture method, children will be bored. Learning English with games can make the learning atmosphere fun and interesting so that students are motivated to learn and understand the material being taught.
\end{abstract}

Key words: games, English and learning

Correspondence author: Ira Miranti, ade_miranti@yahoo.com, Jakarta, Indonesia (1) (\$)

\section{PENDAHULUAN}

Bahasa Inggris penting untuk dikuasai di era milineal ini mengingat bahasa Inggris adalah bahasa internasional. Sebagai bahasa Internasional, Bahasa Inggris banyak digunakan sebagai bahasa penghubung antar negara di dunia dan sarana berkomunikasi secara global. Oleh karena itu, Bahasa Inggris perlu dikuasai, baik secara lisan maupun tulisan. Dengan keterampilan Berbahasa Inggris, Kita juga akan mampu memanfaatkan peluang yang terbuka pada era pasar bebas untuk dapat berkreativitas dan bekerja di luar 
negeri.Jika kita perhatikan pada iklan lowongan kerja terdapat persyaratan untuk pelamar bisa berbahasa Inggris baik lisan maupun tulisan.Hal inilah memicu para pelajar untuk bisa berbahasa Inggris agar mudah mendapatkan perkerjaan di perusahaan yang bonafit nantinya.

Sejalan hal itu pemerintah juga memperhatihan kurikulum pendidikan di bidang pelajaran Bahasa Inggis. Hal ini terbukti dari perubahan nama kurikulum pendidikan seperti KTSP, Kurikulum Tiga Belas, Tematik, yang bertujuan agar pelajaran Bahasa Inggris dapat dicapai dan dikuasai oleh para siswanya. Selain menyediakan buku-buku pelajaran dan LKS, Pemerintah juga menyediakan fasilitas laboratorium bahasa di sekolah-sekolah untuk mendukung kegiatan belajar mengajar gurunya. Bahasa Inggris adalah bahasa yang paling penting dikuasai, mulai dari tingkat pendidikan dasar hingga tingkat pendidikan tinggi mata pelajaran Bahasa Inggris selalu dicantumkan disetiap kurikulumnya, wajib bagi pelajar untuk memperlajarinya. Mata pelajaran Bahasa Inggrispun mata pelajaran yang wajib diujikan pada ujian nasional di SMP dan SMA.Dengan demikian, banyak para pebisnis yang melirik adanya peluang usaha pada dunia pendidikan, mereka mendirikan bimbingan belajar (bimbel) dan tempat kursus bahasa Inggris.

Para orangtuapun tidak kalah ketinggalan untuk memasukkan anaknya ke tempat kursus atau bimbel agar anaknya pintar Bahasa Inggris, mereka juga kwatir jika anak mereka tidak lulus pada ujian nasional. Walaupun biaya kursus atau bimbel tidak murah bahkan dapat dikatakan cukup mahal, mereka tidak peduli yang penting anak mereka lulus ujian, bisa mengikuti pelajaran Bahasa Inggris di sekolah dan mahir berbahasa Inggris.

Menurut Hilgard (dalam Sanjaya 2006:112) mengungkapkan bahwa "Learning is the process by which an activity originates or changed through training procedures (wether in the laboratory or in the natural environment) as distinguished from changes by factors not atributable to training". Bagi Hilgard, belajar adalah proses kegiatan atau prosedur latihan, baik di dalam atau diluar lingkungan alamiah. Secara umum, belajar dapat dipahami sebagai tahapan perubahan tingkah laku yang relatif menetap yang terjadi sebagai hasil pengalaman dan interaksi dengan lingkungan yang melibatkan proses kognitif. Sedangkan menurut Joan Freeman dan Utami Munadar (dalam Andang Ismail 2009:27) mendefinisikan permainan sebagai suatu aktifitas yang membantu anak mencapai perkembangan yang utuh, baik fisik, intelektual, sosial, moral, dan emosional. Definisi diatas menjelaskan tentang pwemainan yang dpaat membantu anak berkembang dalam segala hal. Misalnya, perkembangan fisik, intelektual, sosial, moral, dan emosional. Ini disebabkan karena permainan dapat memutar otak. Pengajaran bahasa Inggris di sekolah dasar masih bersifat konvensional, biasanya para guru hanya mengajarkan kosakata yang ada dibuku lalu ditulis di papan tulis kemudian guru membaca kosakata tersebut siswa mengikuti ucapan guru. Teknik lainnya yang biasa digunakan guru memerintahkan siswa duduk perbaris untuk menirukan ucapan guru.Para siswa kesulitan dalam mempelajari Bahasa Inggris seperti membaca karena antara tulisan dengan bacaan berbeda.Para siswa kesulitan dalam mempelajari Bahasa Inggris seperti membaca karena tulisan dengan bacaan berbeda. Mereka juga kesulitan dalam menulis kosakatanya contoh: "MANGO" dibaca "MENGGO", MONKEY dibaca "MANKI".

Hal ini tentu saja membuat para siswa merasa bosan dan tidak tertarik apa yang diajarkan oleh gurunya bahkan mungkin mereka tidak menyukai pelajaran Bahasa Inggris disebabkan metode pengajaran sang guru yang monoton, statis dan kaku. Menyikapi permasalahan tersebut, maka metode pembelajaran bahasa Inggris harus diubah menjadi 
lebih menyenangkan dan medorong anak-anak mempraktekkan bahasa itu secara lebih aktif, yang terpenting bagi mereka dapat berinteraksi dan berkomunikasi dengan orang lain. Sebagai seorang pendidik kita dapat mengajarkan mereka dengan berbagai macam strategi pengajaran Bahasa Inggris di antaranya bernyanyi, bermain dan mengenalkan kartu bergambar sesuai dengan usia mereka pada tingkat sekolah dasar.

Salah satu teknik yang diajarkan dalam belajar Bahasa Inggris di sekolah dasar adalah bermain karena bermain adalah dunia anak-anak. Pada anak usia sekolah dasar, mereka masih lebih senang bermain dan cenderung tidak suka dengan cara belajar yang terlalu serius. Permainan adalah alat bagi anak untuk menjelajah dunianya, dari yang tidak ia kenali sampai pada yang ia ketahui dan dari yang tidak dapat diperbuatnya, sampai mampu melakukannya. Bermain adalah suatu kegiatan yang serius tetapi mengasyikan, dimana si anak mencobakan diri, bukan saja dalam fantasinya tetapi juga benar nyata secara aktif. (Semiawan, 2008:20). Apabila guru mengajarkan bahasa Inggris dengan metode ceramah maka anak-anak akan merasa bosan. Pembelajaran bahasa Inggris dengan permainan dapat membuat suasana belajar menjadi asik, menarik dan menyenangkan sehingga siswa termotivasi untuk mempelajari dan memahami materi yang diajarkan. Hal yang terpenting adalah bagaimana menarik siswa untuk menyukai pelajaran bahasa Inggris, apabila mereka sudah menyukai dan menyenangi suatu pelajaran maka mereka dapat menguasai pelajaran tersebut.Jadi konsep pembelajaran bahasa Inggris di Madrasah Ibtidaiyah adalah learning by playing (belajar sambil bermain).

\section{METODE PELAKSANAAN}

Pemilihan mitra kegiatan ini didasarkan atas kebutuhan mitra akan pentingnya pembelajaran Bahasa Inggris. Upaya adanya peningkatan nilai Bahasa Inggris pada siswa dan adanya ketertarikan siswa dalam mempelajari Bahasa Inggris. Jadi dengan adanya kegiatan ini dapat menambah wawasan guru dalam mengajar bahasa Inggris. Pendekatan yang dilakukan dalam kegiatan pengabdian masyarakat ini adalah dengan melakukan:

1. Presentasi pengajaran Bahasa Inggris melalui permainan di Madrasah Ibtidayaiyah (MI) Muta'alimin dan MI Hidayatul Mubtadi'in.

2. Tanya jawab tentang pengajaran Bahasa Inggris melalui permainan di Madrasah Ibtidayaiyah (MI) Muta'alimin dan MI Hidayatul Mubtadi'in.

\section{HASIL DAN PEMBAHASAN}

Hasil dari kegiatan pengabdian kepada masyarakat berupa Penggunaan Game (permainan) dalam pembelajaran Bahasa Inggris di Madrasah Ibtidaiyah (MI) Muta'alimin dan Hidayatul Mubtadi'in sangat memuaskan sekali, para guru peserta kegiatan sangat antusias dalam mengikuti kegiatan. Hal ini dikarenakan Pengajaran bahasa Inggris di sekolah dasar masih bersifat konvensional, biasanya para guru hanya mengajarkan kosakata yang ada dibuku lalu ditulis di papan tulis kemudian guru membaca kosakata tersebut siswa mengikuti ucapan guru. Teknik lainnya yang biasa digunakan guru memerintahkan siswa duduk perbaris untuk menirukan ucapan guru.Para siswa kesulitan dalam mempelajari Bahasa Inggris seperti membaca karena antara tulisan dengan bacaan berbeda.Para siswa kesulitan dalam mempelajari Bahasa Inggris seperti 
membaca karena tulisan dengan bacaan berbeda. Mereka juga kesulitan dalam menulis kosakatanya contoh: "MANGO" dibaca "MENGGO", MONKEY dibaca "MANKI".

Hal ini tentu saja membuat para siswa merasa bosan dan tidak tertarik apa yang diajarkan oleh gurunya bahkan mungkin mereka tidak menyukai pelajaran Bahasa Inggris disebabkan metode pengajaran sang guru yang monoton, statis dan kaku. Menyikapi permasalahan tersebut, maka metode pembelajaran bahasa Inggris harus diubah menjadi lebih menyenangkan dan medorong anak-anak mempraktekkan bahasa itu secara lebih aktif, yang terpenting bagi mereka dapat berinteraksi dan berkomunikasi dengan orang lain. Salah satu teknik yang diajarkan dalam belajar Bahasa Inggris di sekolah dasar adalah bermain karena bermain adalah dunia anak-anak. Pada anak usia sekolah dasar, mereka masih lebih senang bermain dan cenderung tidak suka dengan cara belajar yang terlalu serius. Permainan adalah alat bagi anak untuk menjelajah dunianya, dari yang tidak ia kenali sampai pada yang ia ketahui dan dari yang tidak dapat diperbuatnya, sampai mampu melakukannya.

Apabila guru mengajarkan bahasa Inggris dengan metode ceramah maka anak-anak akan merasa bosan. Pembelajaran bahasa Inggris dengan permainan dapat membuat suasana belajar menjadi asik, menarik dan menyenangkan sehingga siswa termotivasi untuk mempelajari dan memahami materi yang diajarkan. Hal yang terpenting adalah bagaimana menarik siswa untuk menyukai pelajaran bahasa Inggris, apabila mereka sudah menyukai dan menyenangi suatu pelajaran maka mereka dapat menguasai pelajaran tersebut.Jadi konsep pembelajaran bahasa Inggris di Madrasah Ibtidaiyah dapat dilakukan dengan learning by playing (belajar sambil bermain).

Setelah mendapatkan sosialisasi dari kegiatan abdimas berupa Penggunaan Game (permainan) dalam pembelajaran Bahasa Inggris para guru sangat antusias untuk menerapkan strategi dalam mengajar bahasa Inggris dengan lebih menarik dan interaktif lagi agar para siswa lebih dapat menerima materi yang diajarkan oleh para guru.

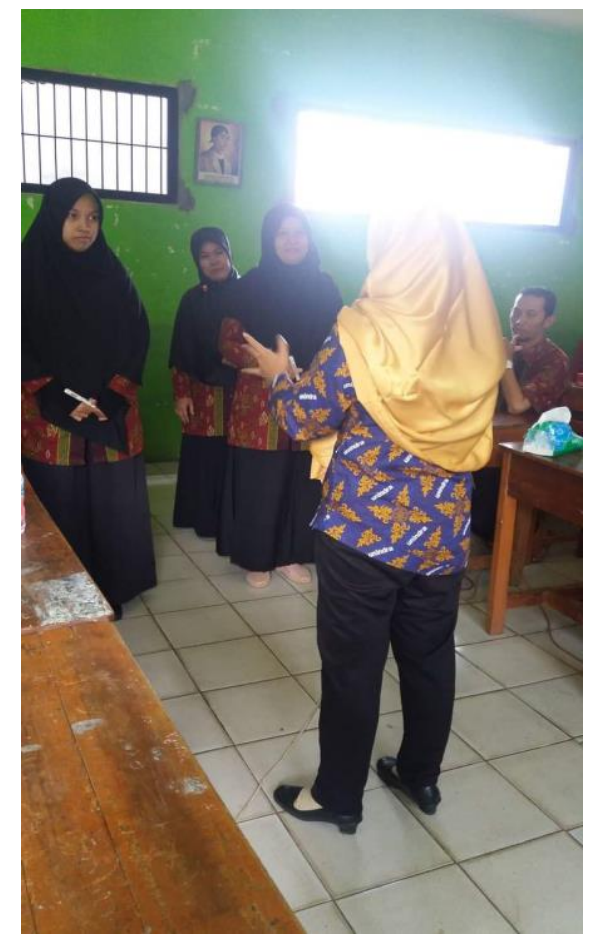

Gambar 1. Tim pelaksana mempraktekkan permainan kepada peserta 


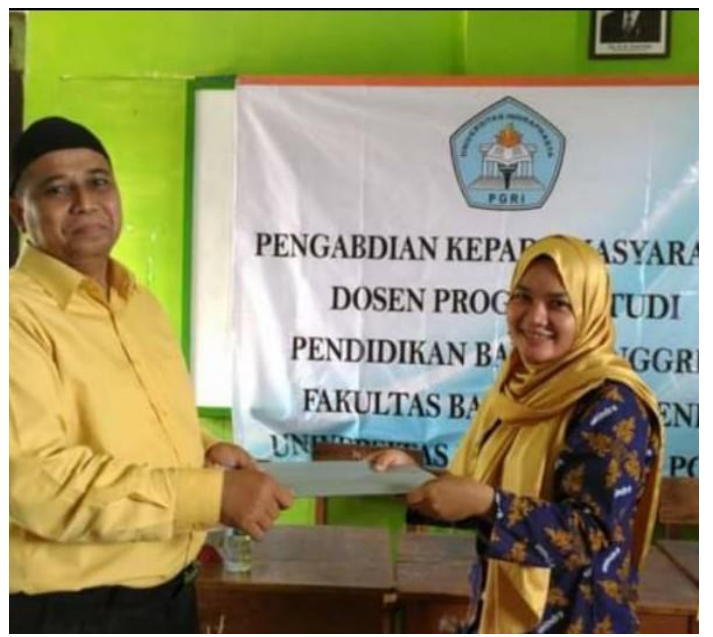

Gambar 2 Penyerahan souvenir kepada Bapak Kepala Sekolah

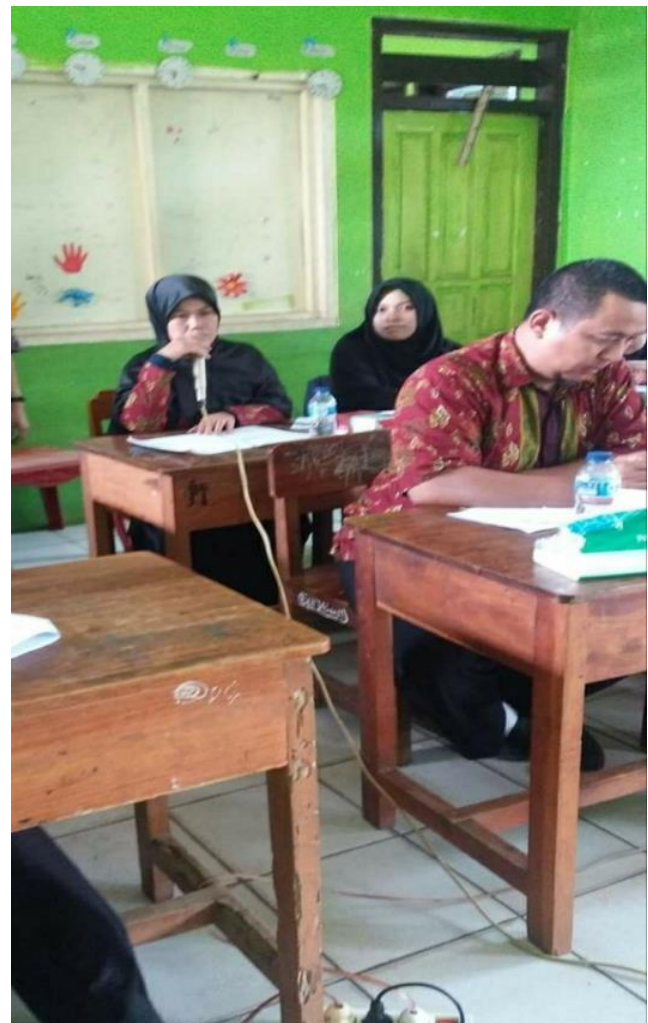

Gambar 3 Aktivitas peserta tanya jawab

\section{SIMPULAN}

Dalam pembelajaran Bahasa Inggris hal yang terpenting adalah bagaimana menarik siswa untuk menyukai pelajaran bahasa Inggris, apabila mereka sudah menyukai dan menyenangi suatu pelajaran maka mereka dapat menguasai pelajaran tersebut.Jadi konsep pembelajaran bahasa Inggris di Madrasah Ibtidaiyah dapat dilakukan dengan learning by playing (belajar sambil bermain). Apabila guru mengajarkan bahasa Inggris dengan metode ceramah maka anak-anak akan merasa bosan. Pembelajaran bahasa Inggris dengan permainan dapat membuat suasana belajar menjadi asik, menarik dan 
menyenangkan sehingga siswa termotivasi untuk mempelajari dan memahami materi yang diajarkan.Metode pembelajaran bahasa Inggris harus diubah menjadi lebih menyenangkan dan medorong anak-anak mempraktekkan bahasa itu secara lebih aktif, yang terpenting bagi mereka dapat berinteraksi dan berkomunikasi dengan orang lain.

\section{DAFTAR PUSTAKA}

Ismail, Andang, (2009). Education Games, Pilar Media: Yogyakarta.

Sanjaya, Wina. (2006). Strategi Pembelajaran. Media Abadi: Yogyakarta.

Semiawan, Conny R, (2008). Belajar dam Pembelajaran Pra Sekolah dan Sekolah Dasar, Indeks. Depdikbud. 